\title{
Evaluation of U10Mo Fuel Plate Irradiation Behavior Via Numerical and Experimental Benchmarking
}

\section{ASME 2012 IMECE}

Samuel J. Miller

Hakan Ozaltun

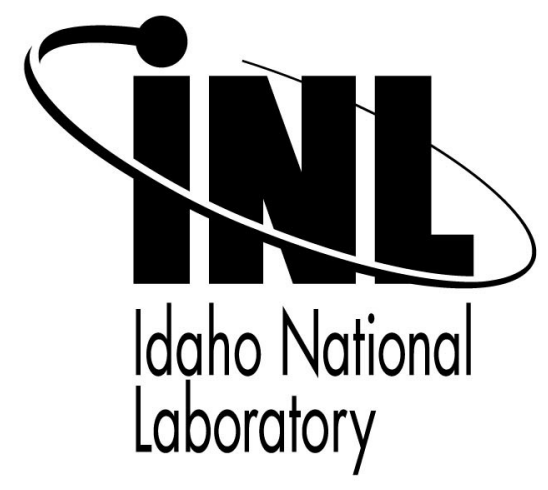

This is a preprint of a paper intended for publication in a journal or proceedings. Since changes may be made before publication, this preprint should not be cited or reproduced without permission of the author. This document was prepared as an account of work sponsored by an agency of the United States Government. Neither the United States Government nor any agency thereof, or any of their employees, makes any warranty, expressed or implied, or assumes any legal liability or responsibility for any third party's use, or the results of such use, of any information, apparatus, product or process disclosed in this report, or represents that its use by such third party would not infringe privately owned rights. The views expressed in this paper are not necessarily those of the United States Government or the sponsoring agency. 


\section{EVALUATION OF U10MO FUEL PLATE IRRADIATION BEHAVIOR VIA NUMERICAL AND EXPERIMENTAL BENCHMARKING}

\author{
Samuel J. Miller \\ Fuel Performance and Design \\ Idaho National Laboratory, P.O. Box 1625 \\ Idaho Falls/ID - 83415, USA
}

\author{
Hakan Ozaltun \\ Fuel Modeling and Simulation \\ Idaho National Laboratory, P.O. Box 1625 \\ Idaho Falls/ID - 83415, USA
}

\begin{abstract}
This article analyzes dimensional changes due to irradiation of monolithic plate-type nuclear fuel and compares results with finite element analysis of the plates during fabrication and irradiation. Monolithic fuel plates tested in the Advanced Test Reactor (ATR) at Idaho National Lab (INL) are being used to benchmark the performance of proposed fuel for several high power research reactors. Post-irradiation metallographic images of plates sectioned at the mid-plane were analyzed to determine dimensional changes of the fuel and the cladding response. A constitutive model of the fabrication process and irradiation behavior of the tested plates was developed using the general purpose commercial finite element analysis package, ABAQUS. Using calculated burn-up profiles of irradiated plates to model the power distribution and including irradiation behaviors such as swelling and irradiation enhanced creep, model simulations allow analysis of plate parameters that are either impossible or infeasible in an experimental setting. The development and progression of fabrication induced stress concentrations at the plate edges was of primary interest, as these locations have a unique stress profile during irradiation. Additionally, comparison between $2 \mathrm{D}$ and $3 \mathrm{D}$ models was performed to optimize analysis methodology. In particular, the ability of 2D and 3D models to account for out of plane stresses which result in 3-dimensional creep behavior that is a product of these components. Results show that assumptions made in 2D models for the out-of-plane stresses and strains cannot capture the 3-dimensional physics accurately and thus 2D approximations are not representative. Stress-strain fields are dependent on plate geometry and irradiation conditions, thus, if stress based criteria is used to predict plate behavior (as opposed to material impurities, fine micro-structural defects, or sharp power gradients), unique 3D finite element formulation for each plate is required.
\end{abstract}

$\bowtie$ Corresponding Author: Samuel.Miller@inl.gov

Phone: (208) 526-1541 || Fax: (208) 526-2930

\section{INTRODUCTION}

In accordance with the Global Threat Reduction Initiative (GTRI), there is an ongoing effort in the RERTR program (Reduced Enrichment for Research and Test Reactors) to reduce the amount of highly enriched uranium (HEU) used in research and test reactors. The development of these fuels requires many design choices to maintain reactor power levels while continuing to meet safety and viability requirements. UMo fuel was selected because of its preferential response during irradiation. Molybdenum extends the cubic gamma phase which provides increased stability under irradiation. Two types of U-Mo fuel have been experimentally tested to meet reactor requirements, dispersion fuel and monolithic plate fuel. Dispersion fuel of U-Mo has shown good performance for low fission densities $\left(4.8 \mathrm{~g}-\mathrm{U} / \mathrm{cm}^{3}\right)$; however, in order to maintain reactivity in some high power reactors, necessary fuel densities $\left(>8.0 \mathrm{~g}-\mathrm{U} / \mathrm{cm}^{3}\right)$ require monolithic plate fuel [1]. The mechanical response of these plates in an irradiation environment must be well described to predict stress dependent behavior such blister formation and plate fracture. Variations in fabrication parameters, geometric irregularities, and irradiation conditions have a significant effect on plate performance and accordingly, comparison between finite element analysis and experimental results was made to characterize plate behavior.

\section{EXPERIMENTAL SETUP}

For the purposes of benchmarking the monolithic fuel performance to support the development of full size reactor elements, scaled down versions of full size plates, named "mini-plates", were fabricated and irradiated in ATR. The goal of these experiments is to optimize fabrication parameters and fully characterize plate behavior in normal and off-normal reactor conditions. Different Uranium - Molybdenum alloy 
compositions were tested and U-10 wt $\%$ Mo was selected based on a compromise between the stress corrosion cracking seen in U-7 wt $\%$ Mo and the loss in ductility and fracture toughness of $\mathrm{U}-12 \mathrm{wt} \%$ Mo alloys.

\subsection{Fabrication}

Fabrication of the monolithic plates requires several steps: casting, zirconium plating, hot rolling, cold rolling, annealing, shearing, and finally bonding to aluminum cladding by means of Hot Isostatic Pressing (HIP) process [2]. Using an induction caster, feedstock is cast in an inert atmosphere into "coupons" of U-Mo. U-Mo coupons are overlaid with zirconium foil and inserted into a rolling canister. The canister is heated to $650{ }^{\circ} \mathrm{C}$ and hot rolled to a thickness of $0.5 \mathrm{~mm}$. After removal from the canister, the U-Mo, $\mathrm{Zr}$ plated foil is cold rolled to a nominal thickness of $0.254 \mathrm{~mm}$ with thickness variations of $0.01-0.02$ $\mathrm{mm}$. This cold working process increases strength and hardness by introducing damage in the form of dislocations. By annealing the fuel plates for 30-120 minutes at a temperature of $650-675^{\circ} \mathrm{C}$, ductility increases, internal stresses are relieved, and homogenous properties are assumed. For modeling purposes, it is assumed that the annealing process removes all residual stresses caused by the casting, plating, and rolling processes. The shearing process is also assumed to be ideal, in that no residual stresses are imparted on the fuel during shearing.

A pocket is milled into one side of the aluminum cladding, Al6061-T6, and sized slightly larger than plate dimensions. With the fuel plate inside, a flat layer of cladding is positioned on the opposing side, and the mini-plates are inserted into a HIP canister. Inert gas is injected into the canister and the can is hermetically sealed, then heated to a temperature of $560{ }^{\circ} \mathrm{C}$ at a pressure of $104 \mathrm{MPa}$. At this temperature, $\mathrm{Al} 6061$ is above the
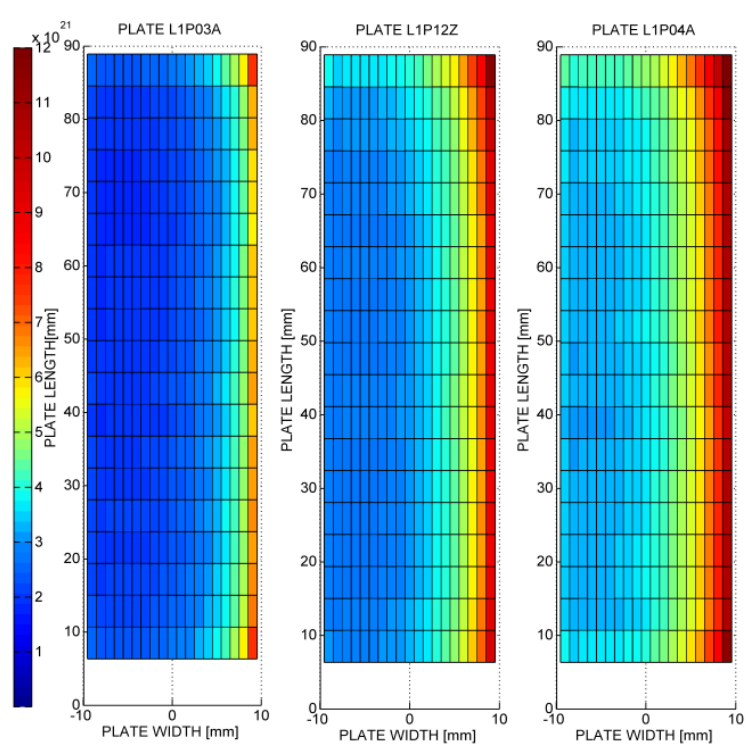

Figure 1 (a) Plate Fission Density [f/ $\mathrm{cm}^{3}$ ] along Length and Width [mm] of Modeled Plates (b) Fission Density at Plate Mid-plane solution temperature $\left(529^{\circ} \mathrm{C}\right)$ but below its solidus temperature $\left(582{ }^{\circ} \mathrm{C}\right)$ [3]. After a holding period of 90 minutes, it is assumed that the aluminum has bonded to the fuel plate and to the opposing cladding, and the plates are cooled to room temperature at a rate of $4.8^{\circ} \mathrm{C} / \mathrm{min}$ [4]. The HIP procedure leads to aluminum properties equivalent to AL6061-O (annealed) [5]. However, due to irradiation and strain hardening during irradiation, the yield strength of the aluminum increases significantly [6]. Models account for property changes by linear interpolation between multiple irradiation and temperaturedependent stress-strain curves.

For the most recent set of mini-plate experiments (RERTR-12) fuel foils were fabricated by cold rolling without an annealing step before HIP. This process minimized variation in foil thickness [7-9]. Plates from the RERTR-12 experiment experienced lower blister temperatures than previous experiments. It has been hypothesized that internal stresses and significant plastic deformation that occurred during the cold rolling process contributed to the lower blister temperatures in RERTR-12 [10,11]. The results presented in this paper are for hot-rolled and annealed fuel foils.

\subsection{Irradiation}

Fabricated plates are arranged in capsules to be irradiated in the ATR. The average fission density of plates ranges from $1 \times 10^{21}$ to $9 \times 10^{21}$ fissions $/ \mathrm{cm}^{3}$ to cover the operational range of LEU fuel [12-15]. Plates analyzed from RERTR - 6, 7, 9 and 10 were positioned with a leading edge facing the center of the reactor, and Monte Carlo N-Particle Transport Code (MCNP) of these plates gives a local to average (L2AR) fission density at 400 nodes on the plate, 20 nodes along plate width and 20 nodes along plate length $[16,17]$ (see Fig. 1a). The plate burn-up profiles for modeled plates (L1P03A, L1P12Z, and L1P04A)

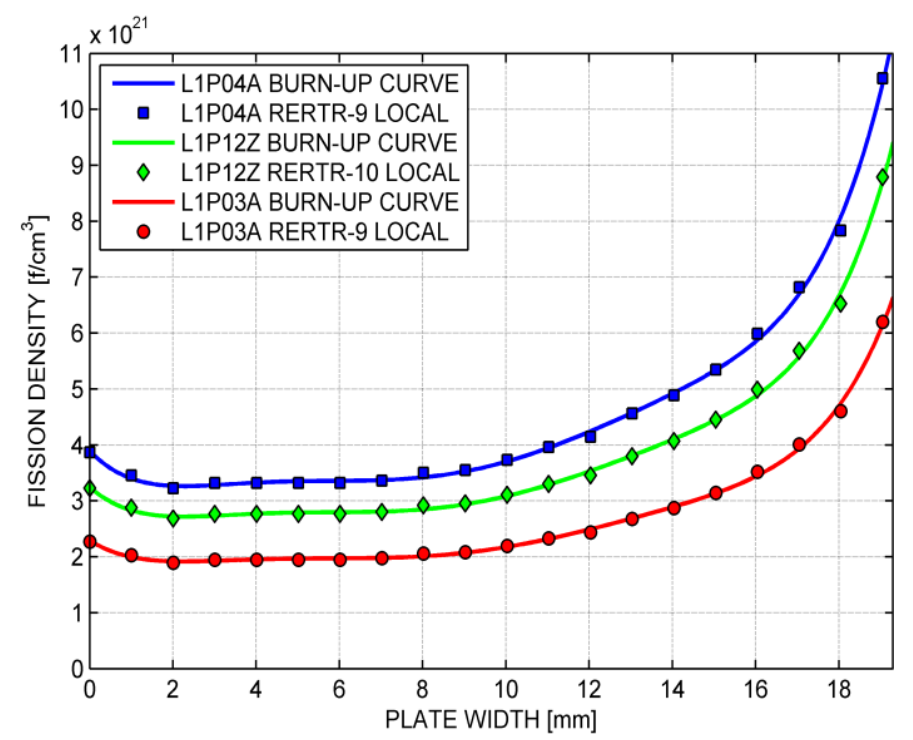


were approximated by a two-dimensional sixth-order polynomial curve fit (see Fig. 1b). Metallographic images were taken of the mid-plane of sectioned plates from experiments in RERTR - 6, 7, 9 and 10 that were fabricated using HIP. The plate thickness was measured based on these images for the plates in Table 1.

Table 1 Irradiation Conditions

\begin{tabular}{cccc}
\hline \multirow{2}{*}{ Plate ID } & Experiment & Fission Density & Fission Rate \\
\cline { 2 - 4 } & (Location) & {$\left[\mathrm{f} / \mathrm{cm}^{3}\right]$} & {$\left[\mathrm{f} / \mathrm{cm}^{3}-\mathrm{s}\right]$} \\
\hline L1F040 & RERTR-6 (B7) & $3.15 \times 10^{21}$ & $2.71 \times 10^{14}$ \\
H1F020 & RERTR-7 (A8) & $4.68 \times 10^{21}$ & $6.03 \times 10^{14}$ \\
L1F140 & RERTR-7 (B7) & $5.15 \times 10^{21}$ & $6.63 \times 10^{14}$ \\
L1P03A $^{\star}$ & RERTR-9 (A6) & $2.88 \times 10^{21}$ & $3.40 \times 10^{14}$ \\
L1P04A $^{\star}$ & RERTR-9 (C6) & $4.80 \times 10^{21}$ & $5.67 \times 10^{14}$ \\
L1F34T & RERTR-9 (B1) & $6.66 \times 10^{21}$ & $6.79 \times 10^{14}$ \\
L1P05A & RERTR-9 (B3) & $5.74 \times 10^{21}$ & $5.85 \times 10^{14}$ \\
L1P12Z & RERTR-10 (C1) & $4.04 \times 10^{21}$ & $5.99 \times 10^{14}$ \\
L2P16Z & RERTR-10 (C3) & $1.91 \times 10^{21}$ & $2.83 \times 10^{14}$ \\
\hline${ }^{\star}$ The plates that were modeled for this study. \\
\hline
\end{tabular}

\section{FUEL PLATE ANALYSIS}

Irradiated plates undergo a number of tests to examine and evaluate performance. Ultrasonic Transmission (UT) scans are taken of HIP plates before irradiation to assess fuel and clad bond. These images were used to measure pre-irradiation length and widthwise dimensions of the fuel foils. Irradiated plates are imaged using neutron radiography in the hot cell at INL in the Materials and Fuels Complex (MFC). These images can reveal whether plates have fractured within the cladding and if major de-bonding occurred at the fuel-clad interface. Neutron radiography images were used to measure post-irradiation length and widthwise dimensions of the fuel foils. Additionally, isotope activity is measured by means of a gamma scan along the width and length of the fuel. The profile of these scans closely matches the thickness measurement of irradiated plates. Some of the plates are sectioned at the mid-plane to analyze the fuel using SEM, TEM, and microscopy. Remaining plates undergo a test called "blister annealing" where plate temperature is increased incrementally by $25^{\circ} \mathrm{C}$ until blisters form on the plate surface [18].

\subsection{Pre-Irradiation Examination}

Ultrasonic scans of fresh fuel were used to determine if a debonded area exists between fuel and cladding after fabrication. Any plates that showed signs of de-bond were not used in experiments. The UT scans allowed for length and widthwise measurement of pre-irradiated fuel. Beam width during scanning is approximately 80 microns. The fuel foil thickness before irradiation is measured by calipers before the plates undergo HIP. Although there is some expected shrinkage of the fuel during HIP, modeling of the fabrication process using initial nominal plate dimensions shows a compression of the fuel thickness by $0.0024 \mathrm{~mm}$ at the cross-section, and a total magnitude of compression $0.242 \mathrm{~mm}$. The thickness contraction is on the order of measurement (calipers) uncertainty, therefore, thickness change during HIP is considered negligible and pre-irradiation thickness is accurate.

\subsection{Post-Irradiation Examination}

After RERTR capsules are irradiated in ATR, they are transferred to the spent fuel pool. Once sufficient cooling has occurred capsules are transferred to the hot cell at MFC. Using the neutron radiography reactor, images are acquired of the plates. These images were used to measure length and widthwise dimensions of the irradiated fuel foils.

Next, plates are oriented side-by-side and gamma scans are taken at approximately 10 locations along the width of each fuel element. The energy peaks can be attributed to various fissions products: Cs-137, Nb-95, Pr-144, Ru-103, and Zr-95.

Finally, plates are cut along the mid-plane, cleaned, and etched. Microscopy images are taken along the fuel width and a montage is created by meshing the individual images.

Using the commercial software AutoCAD 2012, microscopy images of plate mid-planes were analyzed. By dividing the plates into 20 equal sized regions, plate thickness was measured at locations that correspond to the 20 "nodes" developed from the MCNP neutronics analysis. There were several unique aspects of these measurements that give insight into the swelling and creep characteristics of the fuel. Additionally, length and width measurements of the fuel were made using comparisons between pre-irradiated UT scans and postirradiation neutron radiographs.

\subsection{Measurements}

\subsubsection{Length and Widthwise Swelling}

By comparison between UT scans and dimensioned neutron radiographs taken after irradiation, it was determined that swelling in the length and widthwise directions was within the measurement error of $0.75 \%$ lengthwise and $2.31 \%$ widthwise. This uncertainty was associated with the UT scan beam width, the ability to precisely determine plate edges, and the resolution of the images. Although there was no measurable change in plate width and length, isotropic swelling was assumed for simulation models. The restraint of cladding around plate edges constrains the swelling in the length and widthwise directions and simulation results agree accordingly $(0.3 \%$ lengthwise and $0.7 \%$ widthwise swelling). To further assess the extent of widthwise and lengthwise swelling, a consistent measurement 
technique should be employed between pre and post irradiation images to minimize measurement uncertainty.

\subsubsection{Thickness Swelling}

Measurements of irradiated mini-plates are found in Fig. 2. For plates in RERTR-9 and 10, thickness measurements of the foils were made before the HIP process using calipers in three locations along the length. Foil thickness was not recorded for
Plates from RERTR-6 and 7, but it was determined that they fell within the nominal tolerance [19], therefore, nominal thickness was assumed for these plates.

No measurement of fuel thickness was made after the HIP process. Fuel modeling shows that, due to the greater coefficient of thermal expansion of aluminum, during the HIP cooling process, the cladding constricts the fuel and models predict the fuel to decrease in thickness of $0.0024 \mathrm{~mm}$.

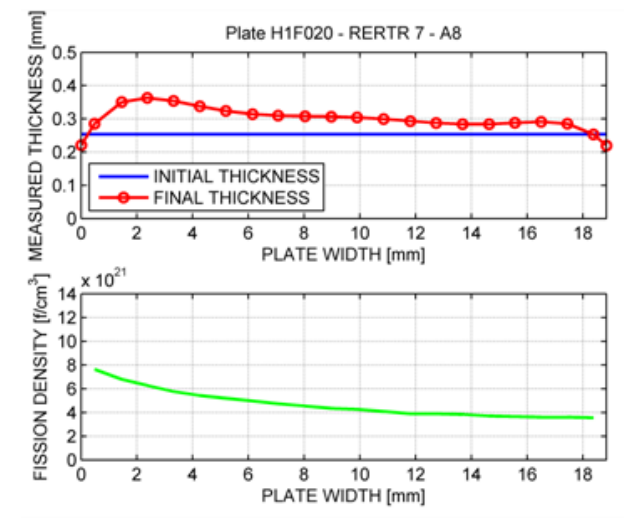

(a) Plate H1F020

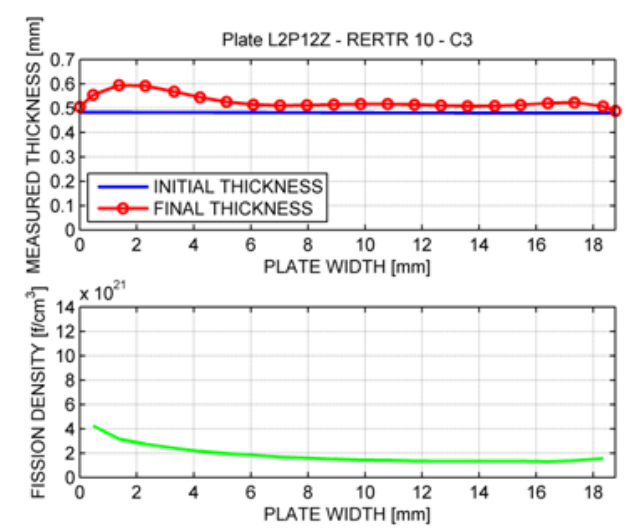

(d) Plate L2P12Z

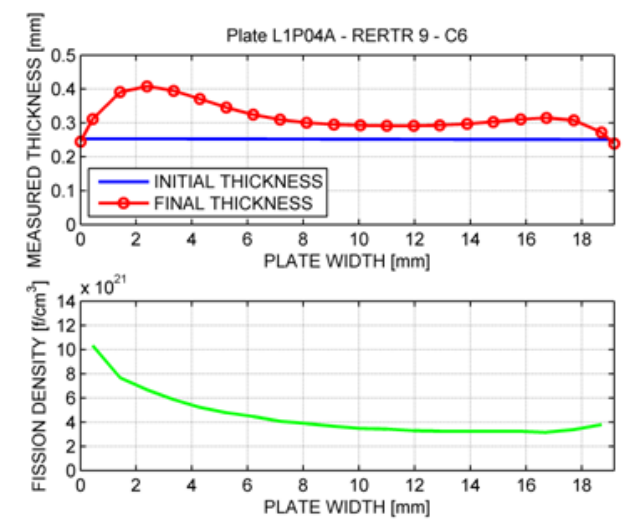

(g) Plate L1P04A *

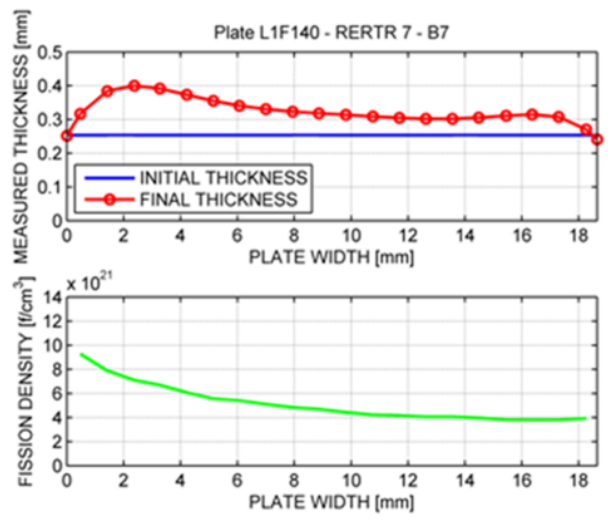

(b) Plate L1F140 - 7B7
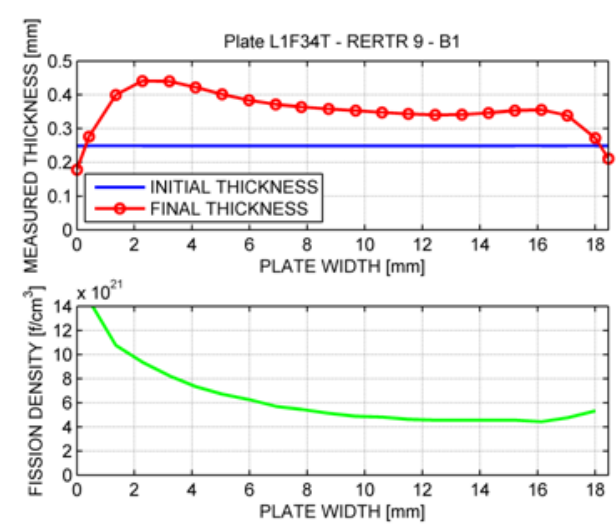

(e) Plate L1F34T

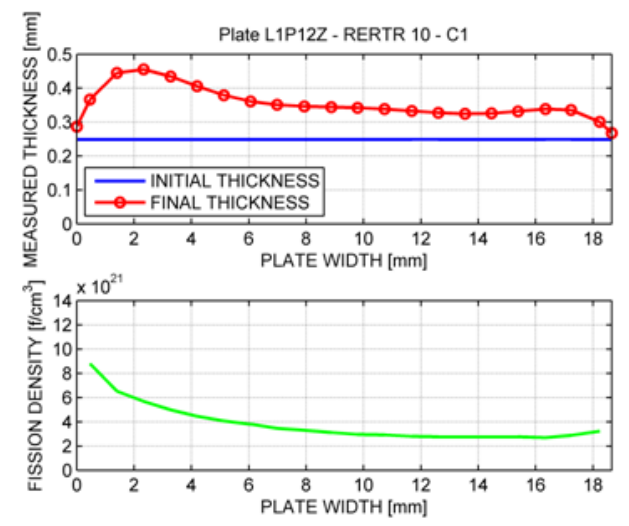

(h) Plate L1P12Z *

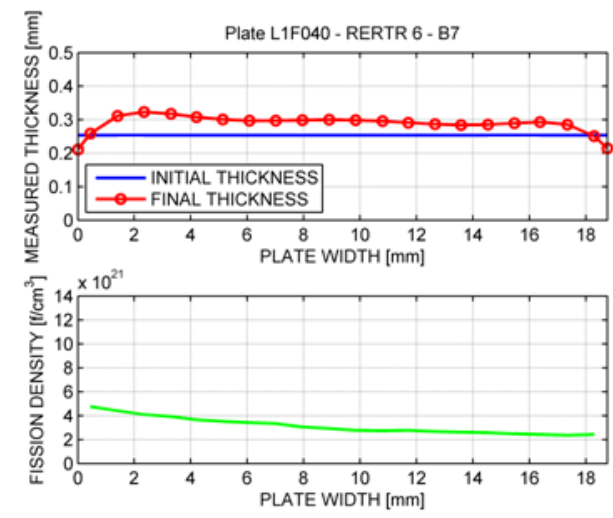

(c) Plate L1F040 - 6B7
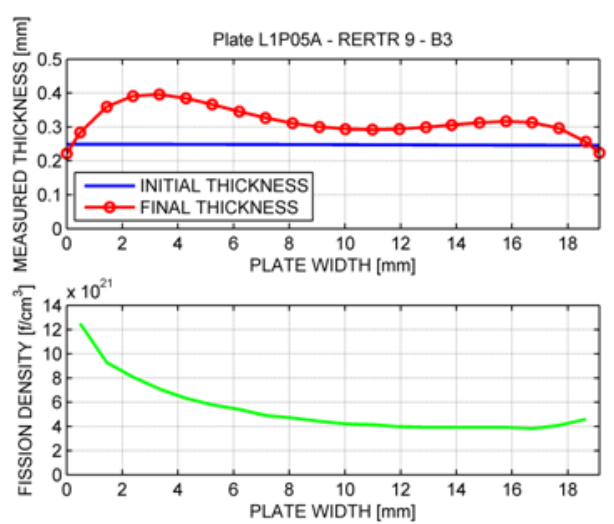

(f) Plate L1P05A
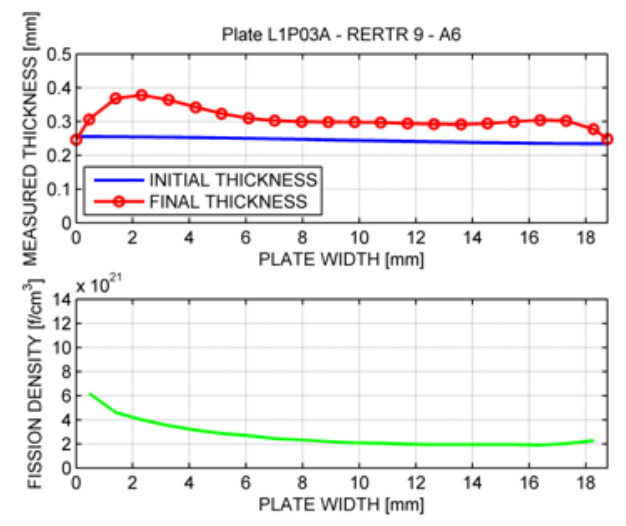

(i) Plate L1P03A *

Figure 2 Thickness Measurements and Fission Densities for Irradiated Mini-plates ${ }^{\star}{ }^{\star}$ Plates L1P04A, L1P12Z and L1P03A were modeled for this study 
The change in plate thickness can be attributed to a combination of fission product swelling and irradiation creep. It is postulated that the constraint of fuel by cladding around plate edges leads to high stresses in the fuel, resulting in creep away from these edges [20]. The result of irradiation creep leads to excessive deformation approximately $1.5-2.5 \mathrm{~mm}$ from plate edges. This phenomenon has been labeled "bulging" or "pillowing". These regions show measured thickness change of up to $80 \%$ (Plates L1F34T and L1P12Z).

It is hypothesized that the variance in thickness change versus fission density is due to variation in fabrication parameters and differences in material properties of both fuel and cladding [10]. Some factors may include: grain size in fuel [21], extent of chemical banding [22] extent of work hardening in fuel before HIP [10], cladding thickness over fuel region, nominal thickness variance, and oxide growth on cladding. This list is by no means comprehensive and but included to give bearing for future analysis.

A decrease in thickness was measured for most plates along transverse edges of fuel foils. A possible explanation is that widthwise swelling leads to excessive creep at plate corners, however, results from FEA modeling do not yield consistent results. Although Aluminum 6061 is very resistant to swelling, is hypothesized that minor swelling of the cladding plays a role in this mechanism [23]. One goal of future modeling efforts is to match experimental results specifically at plate edges.

\section{FINITE ELEMENT ANALYSIS}

\subsection{Model Setup}

Modeling of RERTR mini-plates was done using the commercial finite element package, ABAQUS. A non-linear coupled thermal-mechanical model was developed using C3D8RT elements, consistent with previous modeling techniques of fuel mini-plates [24-26]. Dimensions of the miniplate are shown in in Fig. 3.
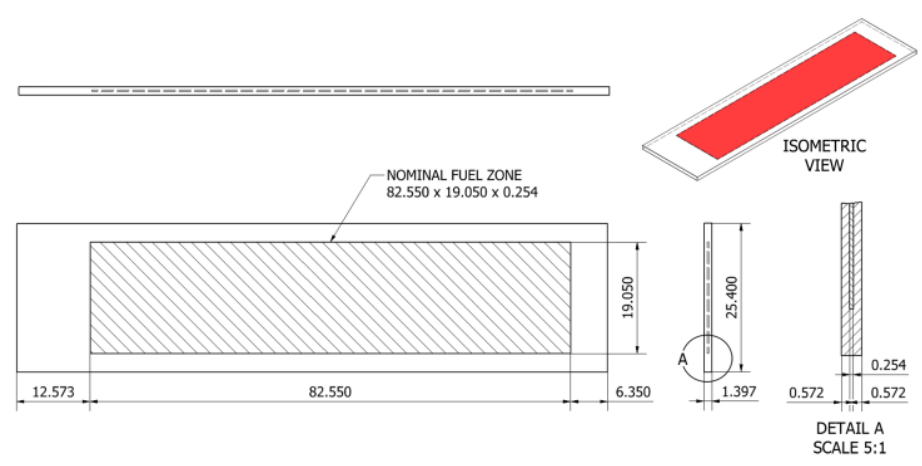

Figure 3 RERTR Mini-plate Dimensions [mm]

\subsection{Mathematical Preliminaries}

The total strain can be decomposed into elastic and inelastic components and can be represented as the sum of the corresponding components of the elastic, plastic, thermal, creep (irradiation and thermal), swelling and initial strains [27].

$\varepsilon_{i j}^{\text {total }}=\varepsilon_{i j}^{e l}+\varepsilon_{i j}^{p l}+\varepsilon_{i j}^{t h}+\varepsilon_{i j}^{c r}+\varepsilon_{i j}^{s w}+\varepsilon_{i j}^{i n}$

This formulation allows the use of classical theories of plasticity (i.e. instantaneous plasticity) in conjunction with thermal creep (i.e. time dependent plasticity). The stress/strain relation of the plate can be expressed as,

$\sigma_{i j}=D_{i j k l} \times \varepsilon_{k l}^{e l}+\sigma_{i j}^{i n}$

where $D_{i j k l}$ is fourth-order tensor constant, commonly referred as material stiffness matrix. For this work, stiffness matrix $D$ is temperature dependent. $\varepsilon_{k l}^{e l}$ is elastic strain tensor, $\sigma_{i j}^{i n}$ is the initial stress, both are second order tensors. In Eqn.2, i,j,k,l are indices.

Substituting elastic strains from (1) into the relation in (2) yields the constitution for the stress fields in the plates,

$\sigma_{i j}=D_{i j k l} \times\left(\varepsilon_{k l}^{\text {total }}-\varepsilon_{k l}^{p l}-\varepsilon_{k l}^{t h}-\varepsilon_{k l}^{c r}-\varepsilon_{k l}^{s w}-\varepsilon_{k l}^{i n}\right)+\sigma_{i j}^{i n}$

In Eqn.3, the initial strain magnitude (i.e. reference state) is zero for the fabrication (for the hot rolled and annealed foil). However, it is non-zero for the irradiation simulation.

Plasticity was defined according to Von-Mises criteria,

$\sigma_{e q}=\left(\frac{3}{2} \sigma_{i j}{ }^{\prime} \sigma_{i j}\right)^{\frac{1}{2}} \geq \sigma_{s}$

The thermal strain tensor was expressed by,

$\varepsilon_{i j}^{t h}=\alpha_{i j}(T) \times \Delta T$

Where $\alpha$ is the tensor that governs the coefficient of thermal expansion, and $\Delta T$ is the change in temperature.

\subsubsection{Thermal Creep Strain}

The Bailey-Norton Law [28], commonly referred as power form of creep law, was used for thermal creep strain,

$\bar{\varepsilon}^{c r}=A \cdot \tilde{\sigma}^{n} \cdot t^{m}$ 
This relation is often expressed in rate form for numerical purposes by taking a derivative with respect to time as follows,

$\dot{\varepsilon}^{c r}=(A \cdot m) \cdot \tilde{\sigma}^{n} \cdot t^{(m-1)}$

This relation is called time hardening formulation of power law creep [29] and was used to implement the thermal creep strain in to the model. In Eqn. 6 and Eqn. 7, coefficients $A, m, n$ are material parameters.

\subsubsection{Irradiation Creep Strain}

Irradiation-induced creep of a material is based on an empirical model which relates the creep rate to the fast neutron flux [neutron $/ \mathrm{m}^{2}-\mathrm{s}$ ] and amplitude of the equivalent stress $[\mathrm{Pa}]$,

$\left(\frac{d \varepsilon}{d t}\right)_{i r}^{c r}=K \sigma^{n} \Phi^{p}$

The parameter $K\left[\mathrm{~m}^{2} /\right.$ neutron-Pa], exponents $n$ and $p$ are determined from the results of the relaxation experiments. Proposed fission enhanced creep formulation [20] relates the creep strain rate to the fission density rate and stress linearly,

$$
\left(\frac{d \varepsilon}{d t}\right)_{i r}^{c r}=A \sigma \dot{F}
$$

Where $\mathrm{s}$ is equivalent stress $[\mathrm{MPa}] ; A$ is a material parameter $\left(A=2.5 \times 10^{-25}\left[\mathrm{~cm}^{3} /\right.\right.$ fission-MPa]) and $F$ is the average fission density rate [fission $/ \mathrm{cm}^{3}-\mathrm{s}$ ] in the plate [20].

\subsubsection{Volumetric Swelling Strain}

Incremental swelling strain is defined as,

$\Delta \varepsilon^{s w}=\frac{1}{3} \Delta \bar{\varepsilon}^{s w} \mathfrak{R}$

$\dot{\varepsilon}_{A}^{s w}=\dot{\varepsilon}_{11}^{s w}+\dot{\varepsilon}_{22}^{s w}+\dot{\varepsilon}_{33}^{s w}=\frac{1}{3}\left(r_{11}+r_{22}+r_{33}\right) \dot{\varepsilon}_{t}^{s w}$

$\mathfrak{R}$ is a matrix with the anisotropic swelling ratios in the diagonal. In Eqn.11, $\dot{\varepsilon}_{\text {total }}^{\text {sw }}$ is the volumetric swelling strain rate is and $r_{11}, r_{22}$ and $r_{33}$ are the directions of the components of the swelling strain rate as explained in [29].

For all plates, swelling was assumed to be isotropic. Volumetric swelling is the sum of the swelling due to solid and gaseous products as explained elsewhere [21, 30, 31].

$\left(\frac{\Delta V}{V_{0}}\right)_{\text {total }}=\left(\frac{\Delta V}{V_{0}}\right)_{g}+\left(\frac{\Delta V}{V_{0}}\right)_{s}$

Swelling due to solid fission products was implemented as,
$\left(\frac{\Delta V}{V_{0}}\right)_{s}=3.5 \times 10^{-21} \cdot f_{d}$

Similarly, gas bubble swelling was implemented according to,

$$
\begin{gathered}
\left(\frac{\Delta V}{V_{0}}\right)_{g}=0.5 \times 10^{-21} \cdot f_{d} \quad \text { if } f_{d}<3 \times 10^{21} \mathrm{f} / \mathrm{cm}^{3} \\
\left(\frac{\Delta V}{V_{0}}\right)_{g}=5.4+2.2 \times 10^{-21} \cdot\left(f_{d}-3 \times 10^{21}\right)+0.51 \times 10^{-42} \times\left(f_{d}-3 \times 10^{21}\right)^{2} \\
\text { if } f_{d}>3 \times 10^{21} \mathrm{f} / \mathrm{cm}^{3}
\end{gathered}
$$

The governing equation for pure conductive heat transfer for the calculation of the temperature fields,

$\rho C_{p} \frac{\partial T}{\partial t}+\nabla \cdot(-k \nabla T)=Q$

Where $\rho$ is the density, $C_{p}$ is the specific heat capacity at constant pressure, $T$ is absolute temperature, $k$ is the thermal conductivity and $Q$ is the non-viscous heat source.

\subsection{Material Properties}

Due to the range of temperatures during fabrication and irradiation, thermo-mechanical properties at these temperature ranges are especially important for model accuracy. When available, material properties were defined as functions of temperature. For the hot rolled foils, it is assumed that fuel foil has little or no directionality; and therefore, material properties are assumed to be isotropic.

Compiled properties for the fuel and the cladding materials which were used in the simulations are presented in [32], while experimental details and more comprehensive information can be found elsewhere [33-42].

\subsection{D vs. 3D Modeling}

Due to the computational efficiency of 2D models, they are often used to produce results that are assumed to represent a Euclidean plane of a 3D model. For this reason, model simulations began using 2D models, with the necessary assumptions made to eliminate the third dimension. ABAQUS then calculates parameters based on a simplified tensor matrix of 3 elements, as opposed to 6 elements for 3D.

When modeling 2D elements, the finite element software will allow you to define the conditions by which there exists a plane of a solid, 3D object. These are typically defined as plane stress, plane strain, and generalized plane strain. The assumptions for each are different. 
For the plane stress condition, the finite element software assumes the there is zero stress in the out-of-plane dimension. $\sigma_{\mathrm{z}}=0$. This is the equivalent of assuming that the object is infinitely thin, and thus, no stress can develop in this direction. For plane strain, the finite element software sets the strain in the out-of-plane direction to zero. $\varepsilon_{\mathrm{z}}=0$. This is essentially assuming that the object is infinitely long in the out-of-plane direction; therefore, no movement in this direction is possible. The third option is a generalized plane strain. For this assumption, an object thickness must be given. The finite element software assumes that the model lies between two bounding planes which move as rigid bodies with respect to each other, thus resulting in a calculated strain for the thickness direction. This is calculated at one "reference node" defined in the model. The final thickness in the out-of-plane direction is a sum of the original thickness, the change in thickness and components for rotation into the plane.

$t=t_{0}+\Delta u_{z}+\Delta \varphi_{x}\left(y-Y_{0}\right)+\Delta \varphi_{y}\left(x-X_{0}\right)$

The resulting strain is then calculated for the entire region, based on the displacement at the designated node.

$\varepsilon_{z z}=\ln \left(\frac{t}{t_{0}}\right)$

By working with plane elements and comparing results between different loading mechanisms and material properties, the change in thickness for the out of plane direction results from application of in-plane stresses (Poisson's ratio), swelling, and creep.

While a generalized plane strain element type can be useful for determining dimensional changes of a part with open edges, in the case of a fuel that is completely surrounded by cladding, it is not accurate. Specifically, the fuel is not free to deform uninhibited in the out-of-plane direction. Cladding at the ends

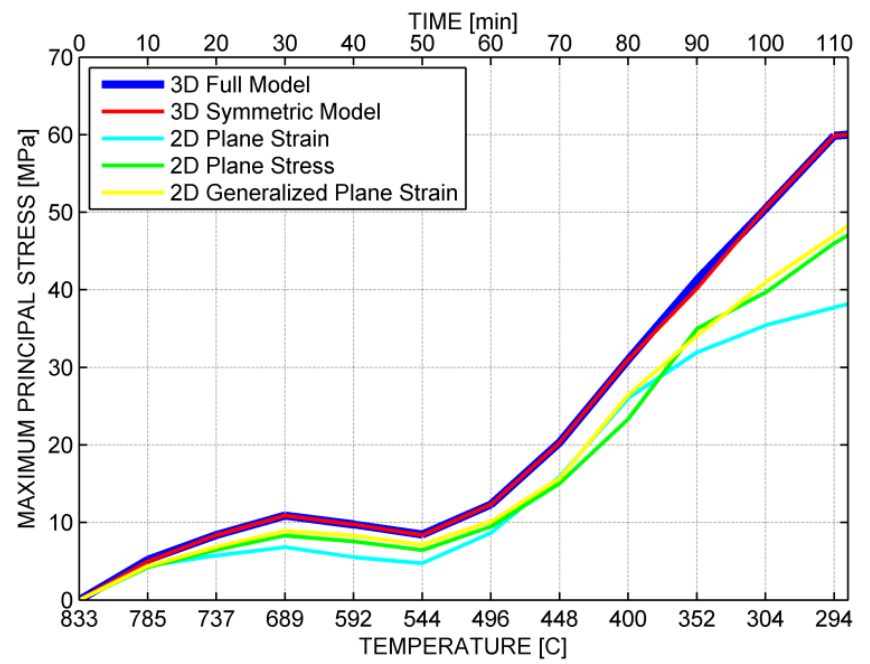

of the plane will constrain movement in this direction. While this may seem to only invalidate strain values in the out-ofplane direction, there is a much more important effect on the inplane stresses. Constraint at the fuel ends due to cladding will result in compressive stresses throughout the fuel in the out-ofplane direction, effecting in-planes stresses by the aforementioned principals. This can be easily observed by comparison to the $3 \mathrm{D}$ models.

As seen in Fig. 4, equivalent stresses in the fuel are underpredicted for 2D Generalized Plane Strain and 2D Plane Stress formulation, and over-predicted for 2D Plane Strain. Measurements for the 3D model are made at the fuel mid-plane for comparison to 2D models. Simplification of 3D models by means of symmetry show no effect on equivalent stress. Slight differences between 3D full and symmetric models were observed for some parameters, due to asymmetric differences in

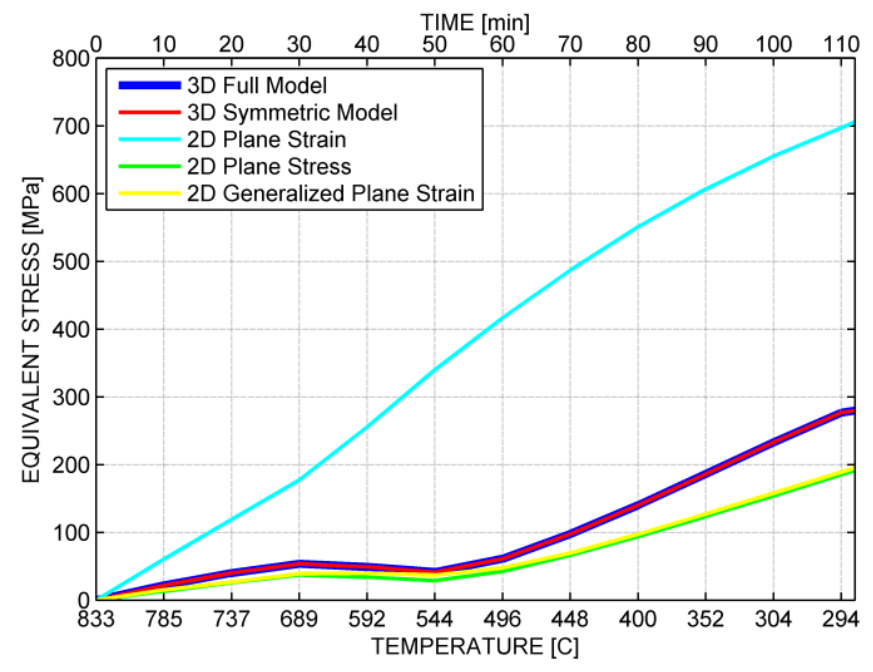

Figure 4 Equivalent Stress of Fuel - Mid-plane during HIP

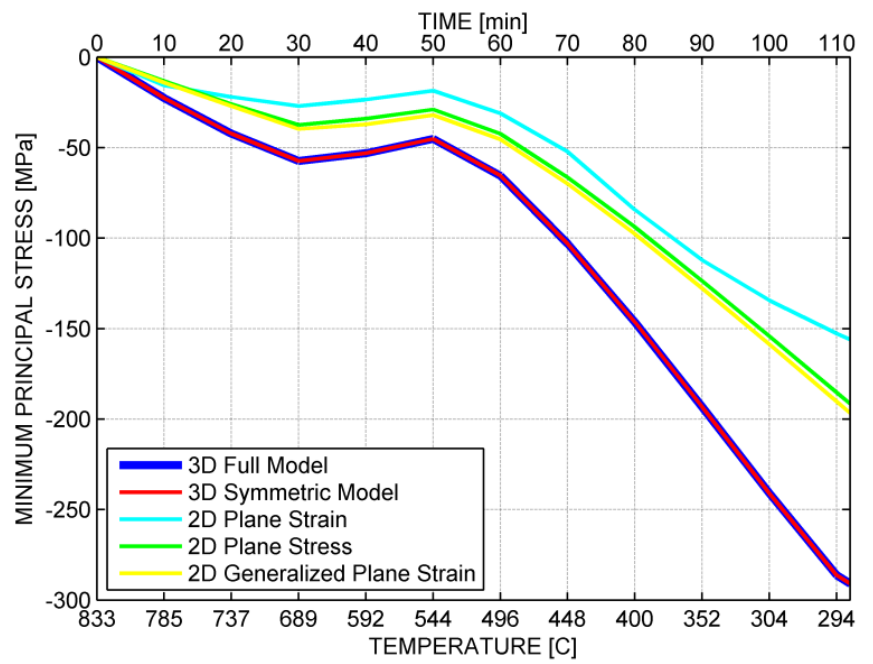

Figure 5 (a) Maximum Principal Stress in Plate Cladding (b) Minimum Principal Stress in Fuel 
cladding length (as shown in Fig. 3) that were not accounted for in symmetric models.

Fig. $5 a$ shows the maximum principal stress observed in the cladding at the fuel mid-plane and shows that while plasticity has occurred in the 3D models (Al6061-O yield stress of 55.15 $\mathrm{MPa}$ at final conditions), plasticity is not yet observed in $2 \mathrm{D}$ models. For maximum principal stress, 2D modeling results in an error between $19.5 \%$ and $36.4 \%$. This shows the obvious shortcomings of 2D models, due to the fact that a ductile failure mode in the cladding is likely strain-based; therefore, plasticity must be accurately modeled. Fig. $5 b$ shows the minimum principal stress in the fuel. This is the dominating stress observed in the fuel and it is under-predicted by 2D models by between $32.4 \%$ and $46.3 \%$.

Although some parameters of 2D models show minimal differences compared to $3 \mathrm{D}$ models, such as thermal deformation, the error associated with very important parameters, such as equivalent and principal stresses, make 2D model unreliable and erroneous when applied to RERTR miniplates. Based on the mathematical simplifications that lead to errors in 2D model, all plates that have cladding completely surrounding the fuel should be modeled in 3D.

\subsection{Irradiation Model}

Three RERTR mini-plates were modeled, L1P03A, L1P12Z, and L1P04A, of varying average fission densities, $2.8 \times 10^{21}$, $4.04 \times 10^{21}$ and $4.8 \times 10^{21}$ [fissions $/ \mathrm{cm}^{3}$ ] respectively. MCNP calculations of in-pile local fission density at 400 nodes on fuel plates was modeled using a two-dimensional, $6^{\text {th }}$ order polynomial to represent local isotropic swelling of the fuel as shown in Fig. 1. Irradiation hardening of the cladding was modeled using linear interpolation between irradiationdependent stress-strain curves at $50^{\circ} \mathrm{C}$ and $150{ }^{\circ} \mathrm{C}[6]$.

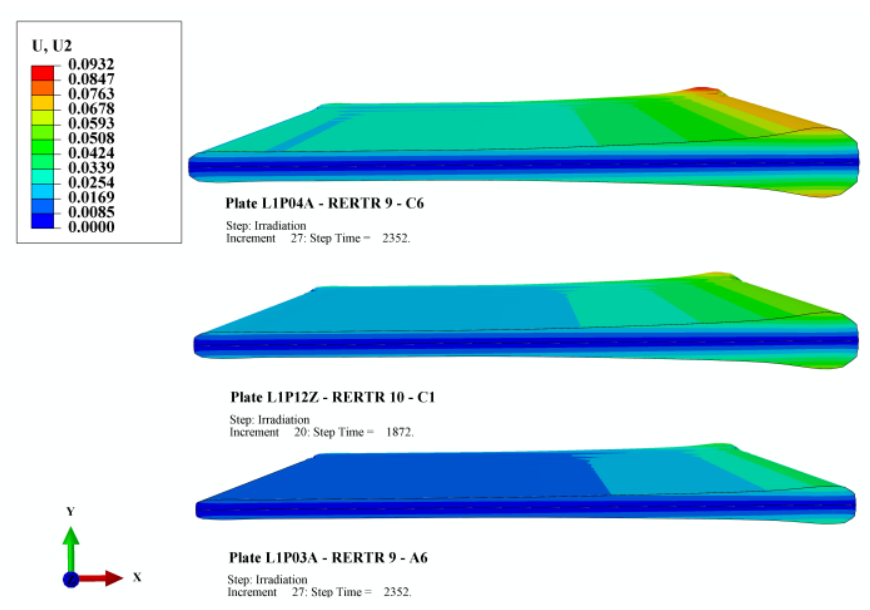

By implementing an elastic-plastic strain formulation, strain hardening of the fuel is accounted for. Experiments show that although the cladding is received with a T6 heat treatment, the HIP process anneals the cladding and the cladding is in the fully annealed $\mathrm{O}$ heat treatment at the end of HIP [5]. By the end of irradiation, the cladding has hardened significantly; consequently, due to the stress dependence of irradiation creep, time-dependent properties must be used to accurately represent the time-dependent stress profile during irradiation.

Fig. $6 a$ represents the change in thickness of the plates at the end of irradiation. Plates are arranged in decreasing fission density from top to bottom. Comparison with Fig. $6 b$ shows that as the fuel swells, the equivalent stress correspondingly increases. Stress concentrations are located near areas of greatest fission density and therefore are most susceptible to a stress-based failure. A cut at the mid-plane was made for visualization purposes.

It can be seen in Fig. $7 a$ that high compressive stresses $(-20<$ $\left.\left[\sigma_{2}, \sigma_{3}\right]<-300[\mathrm{MPa}]\right)$ are observed for the mid and minimum principal stresses $\left(\sigma_{2}, \sigma_{3}\right)$ and the maximum principal stress $\left(\sigma_{1}\right)$ is in either tension or compression, depending on location $\left(120<\sigma_{1}<-120\right)$. Comparison between Fig. $7 a$ and Fig. $7 b$ shows that the maximum principal stress $\left(\sigma_{1}\right)$ almost exactly corresponds to the thickness direction $\left(\sigma_{22}\right)$, and the mid and minimum principal stresses $\left(\sigma_{2}, \sigma_{3}\right)$ correspond to the length and widthwise directions $\left(\sigma_{11}, \sigma_{33}\right)$, respectively.

It has been hypothesized that a tensile state in the fuel is a contributing factor for blister formation. If sufficient fission gas is present, a tensile state will permit gaseous diffusion along grain boundaries, eventually resulting in blister formation [43]. Although the magnitude of the largest stresses in the fuel are compressive nearly everywhere, near the foil lengthwise ends, low compressive stresses in the width and lengthwise directions

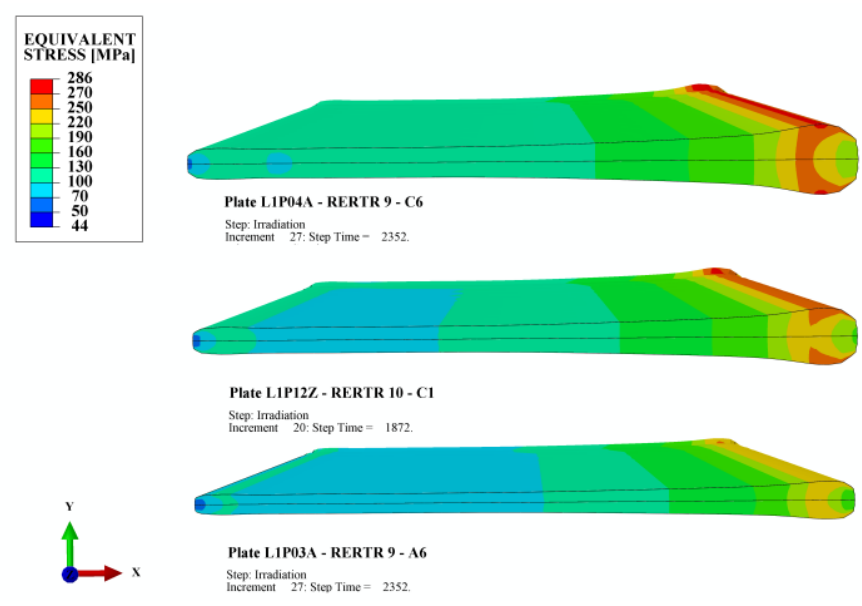

Figure 6 Irradiation Results of Modeled Plates (a) Thickness Growth (b) Equivalent Stress

(Deformation Scaled by factor of 12) 

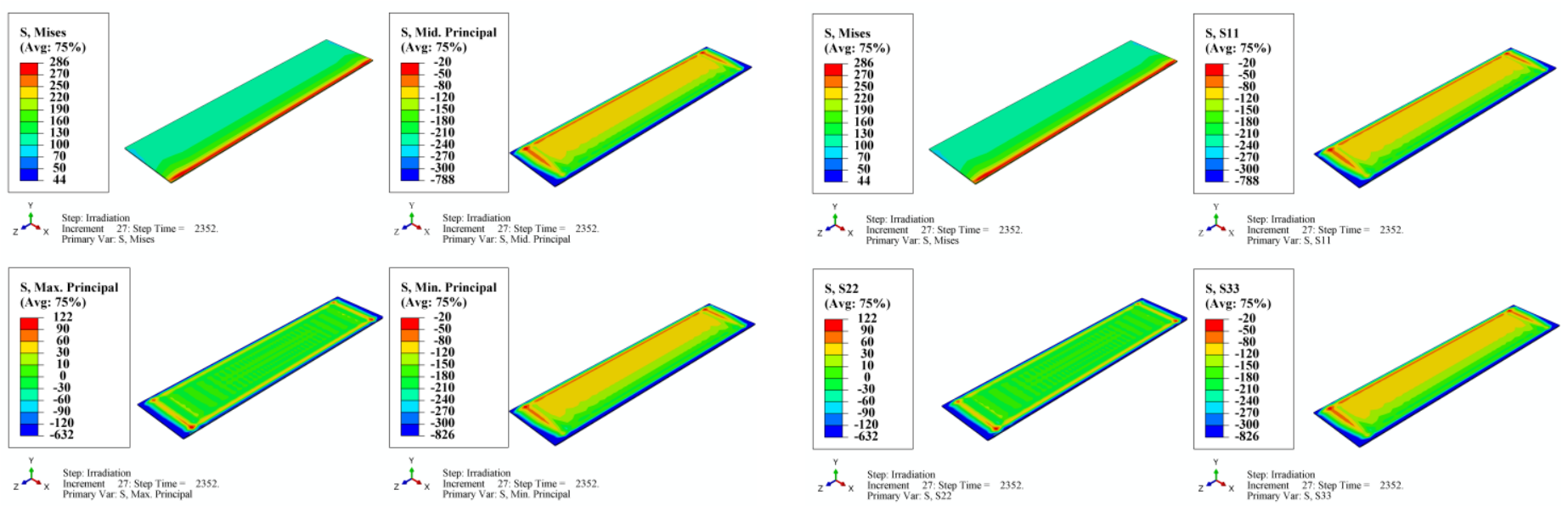

Figure 7 Plate L1P04A (a) Equivalent and Principal Stresses in Fuel (b) Equivalent and Directional Stresses in Fuel

$\left(\sigma_{11}, \sigma_{33}\right)$ and a tensile state in the thickness direction $\left(\sigma_{22}\right)$, lead to a tensile-dominant stress state (Fig. $7 b$ ). Future work will be focused on analyzing this region in greater detail, and understanding how these stresses develop during blister testing.

Plate and cladding temperature plays a role in finite element analysis for evaluating thermal expansion, as well as temperature dependent properties. The coolant is not modeled but coolant temperature is included as a boundary condition for simplicity. Fission heat is modeled as a body heat flux. Temperatures can be seen in Fig. $8 a$.

As the fuel swells, cladding stresses increase, especially at fuel edges where the constraint of fuel is limited by the strength of the cladding. Cladding stress reaches $259[\mathrm{MPa}]$ in Plate L1P04A and slightly lower for plates of lower fission density. The cladding is in tension at these locations. Even though the cladding hardens significantly, it remains sufficiently ductile for a strain-based failure mechanism to dominate [6]. This can be seen in stress-strain curves of aluminum subjected to high neutron fluence that do not show brittle fracture. However, the maximum percent elongation decreases with increasing neutron flux (from $18-22 \%$ to $\sim 12 \%$ ) [6].The equivalent stress in the fuel and cladding can be seen in Fig. $8 b$ and the plastic equivalent strain can be seen in Fig. $8 c$.

\subsection{Model and Experiment Comparison}

The results predicted by finite element analysis have been compared to a number of experimental results and show relatively good agreement. Edges and corners are more likely to produce blisters, and although the blister test has not been yet been modeled for these plates, susceptible regions have been identified by FEA on plate edges and corners, where tensile stresses are largest and compressive stresses are lower. Finite element analysis of the blister test is a goal for future development, and may help shed light on the magnitude of tensile stress required for fission gas release.

Predicting the fracture of plates will prove more difficult than predicting the blister temperature. Insufficient material data is available to accurately model the fracture strength of the fuel. Additionally, understanding of bulk properties may not prove useful due the microscopic effect of micron-size bubbles that may initiate cracks. Sub-modeling may be pursued in the future to analyze bubbles and their growth and movement from a smaller scale.

The most direct means of comparison of FEA to experimental results is by comparing thickness measurements made from PIE metallographic imaging. When experimental measurements
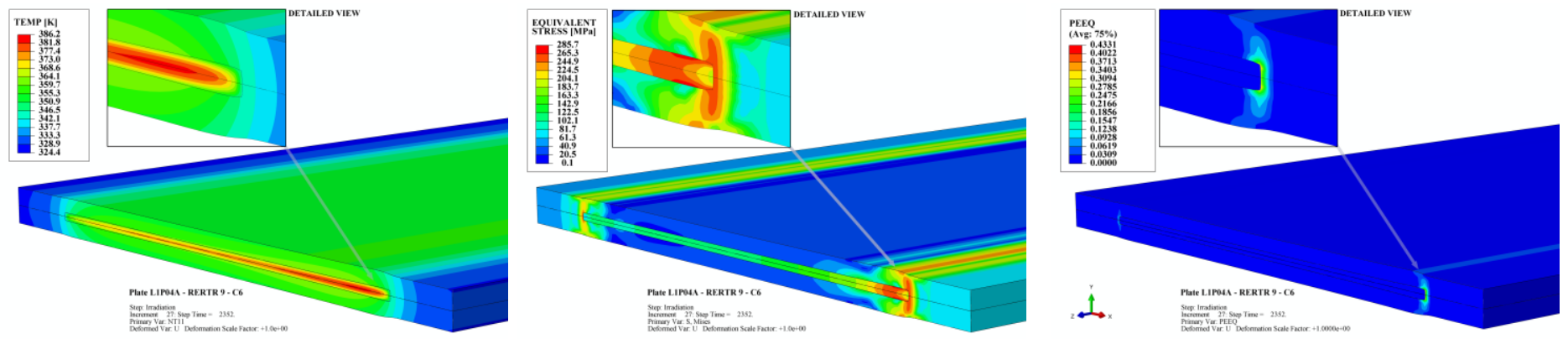

Figure 8 Plate L1P04A (a) Temperature (b) Equivalent Stress (c) Equivalent Plastic Strain 

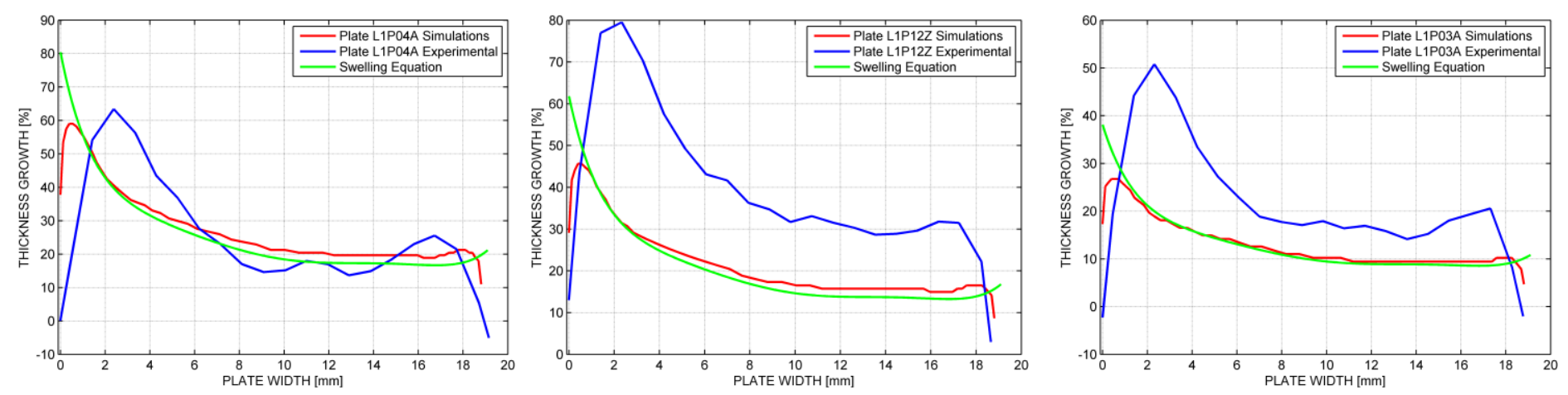

Figure 9 Fuel Swelling: Model and Experiments (a) L1P04A (b) L1P12Z (c) L1P03A

results are compared to each other, relatively large variance is seen. This result points to inconsistency between fuel foils that may have been caused at some point of the fabrication process. Indeed, fuel material has been obtained from various sources and the slight differences in the production of fuel foils may influence dimensional changes in the fuel. As noted earlier, some factors may include: grain size in fuel [21], extent of chemical banding [22], extent of work hardening in fuel before HIP [10], cladding thickness over fuel region, nominal thickness variance, and oxide growth on cladding. This list is by no means comprehensive and but included to give bearing for future development. Comparison between models and experimental results can be seen in Fig. 9.

The irradiation models have been developed based on previous efforts to characterize irradiation swelling and creep [20, 21]. These characterizations contain assumptions, specifically, that swelling is only fission density dependent, and that irradiation creep has linear stress dependence. It has been documented that gaseous swelling has stress dependence, due to hydrostatic pressure imposed on the gas bubbles [44-49]. Additionally, in the low stress range, a power law formulation of irradiation creep rate is typically characterized by a stress exponent of 1 , diffusional creep being the dominating mechanism (NabarroHerring or Coble creep). However, at large stresses, the stress exponent of 4-5 and as high as 7 have been documented for various Uranium alloys [46, 50-55]. This mechanism is attributed to dislocation creep.

It is important that these factors are accounted for in future models and characterization efforts to capture mechanical behavior accurately. It was emphasized that "The simplified approaches such as linearizing the fuel swelling without considering the effects of temperature, stress, and microstructure are not effective in representing the fuel database, let alone extrapolating it to new operating conditions" in a recent study entitled "On the significance of modeling nuclear fuel behavior with the right representation of physical phenomena" by Karahan [56]. In addition, developments should be carried out in 3D model space, due to the inability of $2 \mathrm{D}$ models to accurately represent 3D phenomenon as shown in Sec. 4.4.

\section{INVESTIGATION OF IN-PILE PLATE ORIENTATION}

\subsection{Background}

A major change occurred in configuration of the plates in the reactor core with the RERTR-12 experiment. In all experiments prior to RERTR-12, the plates were oriented "edge on" towards core center. That configuration resulted in non-uniform distribution of power and burn-up within the plates. To reduce this effect and obtain more uniform distribution, RERTR-12 plates were irradiated in a "face on" configuration towards the core center.

It has been hypothesized that different in-core plate configurations might be associated with different stress fields, which, in turn, can lead to differences in blister threshold temperatures [11]. To evaluate this hypothesis and assess stress fields of the plates in "edge on" versus "face on" configurations, several simulations were performed on plates fabricated with hot-rolled and annealed foils.

Because the irradiation models of the plates fabricated with cold-rolled foils are in development, a sensitivity study was performed on plates fabricated with hot-rolled and annealed foils (i.e. RERTR-10 plates). Because the foils in these plates are annealed prior to the HIP process, it is assumed that there are no residual stresses and material anisotropy before the HIP canning. Although this assumption is not entirely accurate, it is expected that annealing will reduce the material anisotropy and relieve some of the stresses caused by the hot-rolling process [25]. Consequently, hot-rolled and annealed foils should have smaller stress gradients, less anisotropy, and more-uniform microstructure than the cold-rolled foils.

As mentioned previously, cold-rolling simulations showed evidence of residual stress in considerable magnitudes and include significant stress gradients [10]. Therefore, a quite different HIP stress profile is expected. The purpose of this section is to evaluate whether edge-on versus face-on irradiation configurations create significant changes in structural response. 


\subsection{Model}

Simulations were accomplished using a plate with the average fission density of $4.04 \times 10^{21}$ fissions $/ \mathrm{cm}^{3}$. The burn-up profiles were selected to be representative of the plates in the edge-on and face-on configurations. Swelling was modeled as an isotropic volumetric strain rate using the swelling equation and the local-to-average fission rates across the width of the plate (shown in Fig. 10). Each plate was irradiated for 98 days at an average fission rate of $5.7 \times 10^{14}$ fissions $/ \mathrm{cm}^{3}$-s. Material properties and the governing mathematical formulations have been previously documented.

\subsection{Results and Discussion}

The largest tensile stress (largest maximum principal stress), equal to $127 \mathrm{MPa}$, was predicted for the plates in the edge-on configuration. This compares to $77 \mathrm{MPa}$ for the plates in the face-on configuration. Maximum equivalent stress for the edgeon plate is $286 \mathrm{MPa}$, compressive, at the high burn-up edge. For the face-on plates, the maximum equivalent stress is 107 $\mathrm{MPa}$, compressive. The yield stress for $\mathrm{U}-10 \mathrm{Mo}$ is $760 \mathrm{MPa}$ at $94^{\circ} \mathrm{C}$ and $655 \mathrm{MPa}$ at $205^{\circ} \mathrm{C}$. The operating temperature of the fuel is between 142 and $167^{\circ} \mathrm{C}$, depending on location. All directional, principal, and equivalent (Von-Mises) stresses in the plates for both irradiation conditions are below the yield strength; thus, no plastic yielding is seen in the plate simulations. Despite the fact that none of the principal stresses exceeds the yield stress, it is still possible for yielding to occur from the combination of stresses. For this reason, the equivalent stress was calculated and is shown in Fig. 11.

Stresses in the cladding are found to be similar for plates in both orientations. Yielding of the aluminum occurs around all of the sides of the fuel for both irradiation conditions. It is assumed that the cladding is sufficiently ductile at the end of
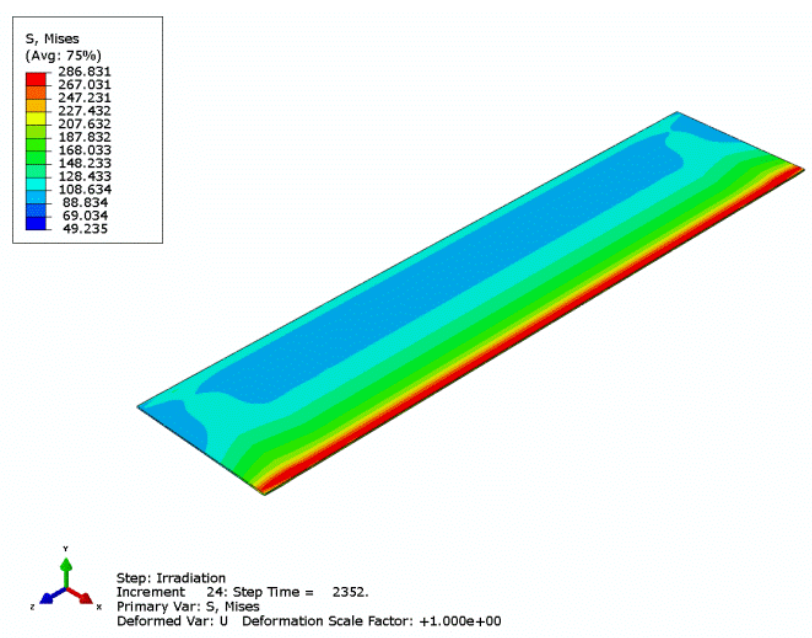

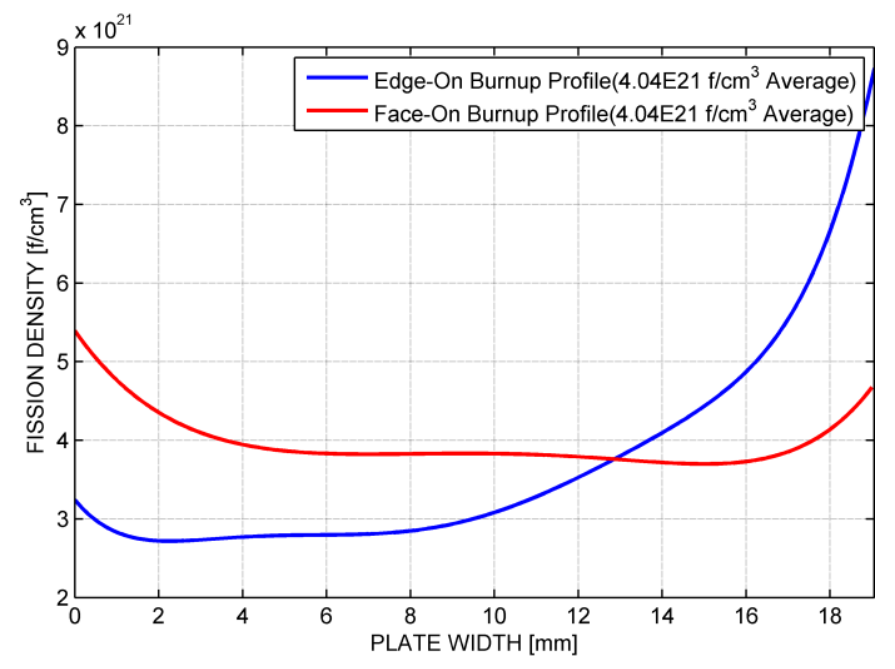

Figure 10 Burn-up Profiles for Plate Orientations

irradiation that a strain-based failure will dominate. For plates in edge-on orientation, the plastic strain is $\sim 0.2$ at most locations on the high burn-up edge and reaches a maximum of 0.372 at the corners of the plate. For plates in the face-on orientation, plastic strain has a maximum of 0.104 . This shows that cladding cracking is more likely to occur in plates with edge-on orientation; however, simulations deviate from experimental measurements of the plate thickness at the plate sides. Thus, strain values of the cladding should be used with caution if the attempt is to apply strain-based failure criteria.

In the thickness direction $\left(\sigma_{22}\right)$, a tensile state is observed from the onset of irradiation at locations just inside the ends of the fuel. The stress magnitude along thickness direction $\left(\sigma_{22}\right)$ grows from slightly compressive at the beginning of the irradiation to a localized maximum (near the top and bottom of the plates) of $74 \mathrm{MPa}$ and $123 \mathrm{MPa}$ for the plates in the face-on and edge-on orientations, respectively. Assuming that the yield strength of

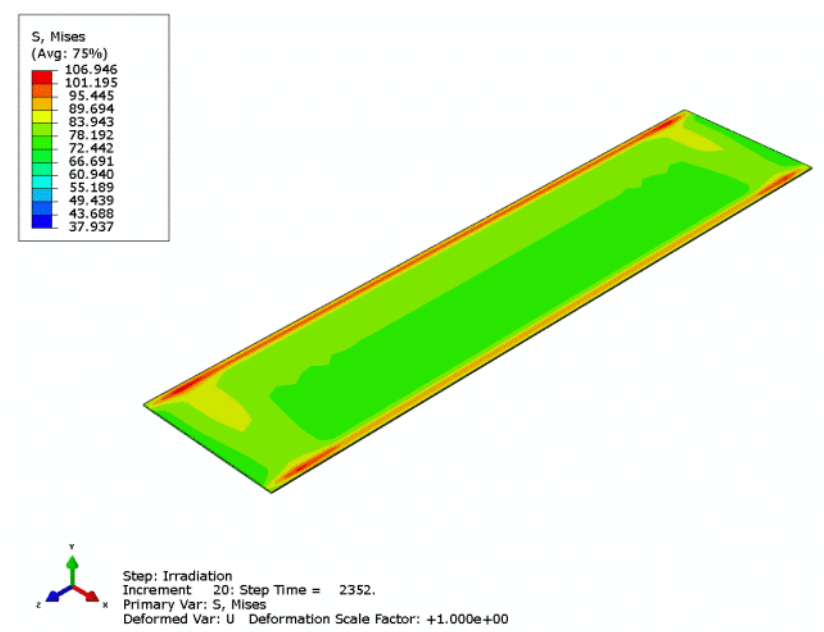

Figure 11 Equivalent Stress on Irradiated Plates (a) Edge-on Configuration (b) Face-on Configuration 
$\mathrm{U}-10 \mathrm{Mo}$ at this temperature is around $700 \mathrm{MPa}$, no timeindependent plasticity (i.e., Von-Mises plasticity) is anticipated. It was found that the majority of the plate has very little stress in the thickness direction $\left(\sigma_{22}\right)$, and there is compressive stress at the plate perimeter (up to $-390 \mathrm{MPa}$ ). For locations where a tensile state is observed along the thickness direction, the stresses in the other two directions (along the length and width of the foils) are compressive. At the beginning of irradiation, the magnitude of these stresses is between -249 and $-285 \mathrm{MPa}$ for $\sigma_{11}$ (along plate width); and -251 and $-268 \mathrm{MPa}$ for $\sigma_{33}$ (along plate length). Shear stresses have a magnitude less than $30 \mathrm{MPa}$ at all times; thus, shear stresses should have little or no contribution to the overall stress state of the foils.

\subsection{In-Pile Orientation Summary}

Irradiation behaviors of the plates with two different configurations were benchmarked. It was shown that the magnitude of stresses is greater in the fuel plates in the edge-on orientation; however, the same model cannot be used to make an accurate assessment for the lower blister temperatures observed in the RERTR-12 "cold-rolled" plates. In particular, it was shown that the magnitude of stresses is greater for the fuel plates in the edge-on orientation. Although the blister-anneal tests for these plates have not yet been modeled, extrapolation of the previous results [26] suggests that the magnitude of tensile stress during blister testing will be higher for the plates in the edge-on orientation.

For plates irradiated in the face-on configuration, the swelling strain is distributed more or less uniformly across the entire plate. Consequently, no localized stress concentration was found on foils which were irradiated in the face-on orientation. More definitive criteria for the blister mechanism and material property data will be necessary to predict the exact blister conditions. This work is in progress.

\section{CONCLUSIONS}

Length and widthwise swelling was measured to be less than measurement uncertainty of $0.75 \%$ and $2.3 \%$, respectively. Models show length and widthwise swelling of approximately $0.3 \%$ and $0.7 \%$, respectively. To further assess the extent of widthwise and lengthwise swelling, a consistent technique should be employed to obtain data for pre and post irradiation measurements to minimize measurement uncertainty.

Measurements of PIE metallographic images show excessive deformation of up to an $80 \%$ change in thickness found approximately 1.5-2.5 [mm] from plate edges. This effect changes the burn-up profile and could lead to adverse effects in fuel performance and variability in plate power.
2D modeling cannot accurately describe the 3D physics of fuel plates and should not be used in future development. Resulting errors of stress range from $19 \%$ to $46 \%$ in comparison to $3 \mathrm{D}$ models. Previous work using 2D models should be evaluated based on assumptions used to eliminate the third dimension and assessed accordingly.

Future characterization of swelling and creep laws should address the concerns outlined in Sec. 4.5 to accurately capture the mechanical behavior during irradiation.

Extrapolation of the previous results [26] suggests that the magnitude of tensile stress during blister testing will be higher for the plates in the edge-on orientation. The irradiation behavior of plates with hot-rolled and annealed foils (i.e., RERTR-10) and the effect of the irradiation configuration (face-on versus edge-on) require more definitive criteria for the blister mechanism. However, the same model cannot be used to make accurate assessment for the lower blister temperatures observed in the RERTR-12 cold-rolled plates.

The results discussed in this paper are relevant to the plates with hot rolled and annealed foils only. The results for cold rolled foils will be considerably different [10]. The accuracy of the results presented in this article relies on the availability and accuracy of the mechanical property data. Even though the current model has provided reasonable results for the mechanical behavior of the plates during irradiation, the authors still acknowledge that updating the model with more accurate property data would yield better results.

\section{NOMENCLATURE}

$\begin{array}{ll}A & \text { Power law multiplier } \\ C_{p} & \text { Specific Heat } \\ D_{i j k l} & \text { Elasticity matrix } \\ E & \text { Modulus of Elasticity } \\ h & \text { Heat Transfer Coefficient } \\ k & \text { Thermal conductivity } \\ m & \text { Time exponent } \\ n & \text { Stress exponent } \\ Q & \text { Heat source } \\ t & \text { Time } \\ T & \text { Temperature } \\ u_{i j} & \text { Displacement } \\ \alpha k l & \text { Tensor for coefficient of thermal expansion } \\ \varepsilon_{i j} & \text { Strain Tensor } \\ \varepsilon_{\mathrm{pl}} & \text { Equivalent plastic strain } \\ \varepsilon_{c r} & \text { Equivalent creep strain rate } \\ \rho & \text { Density } \\ \sigma_{i j} & \text { Stress tensor } \\ \sigma_{i j}, & \text { Deviatoric Kirchhoff stress } \\ \sigma_{s} & \text { Yield stress }\end{array}$




\section{ACKNOWLEDGMENTS}

Author would like to thank Adam B. Robinson for his work with post-irradiation examination and Pavel G. Medvedev and Daniel Wachs for useful discussions concerning nuclear phenomenon. This work was supported in part by an allocation of computing time from the High Performance Computing facilities at Idaho National Laboratory.

\section{US DEPARTMENT OF ENERGY DISCLAIMER}

This manuscript has been authored under Contract No. DEAC07-05ID14517 with the US Department of Energy. The US Government retains and the publisher, by accepting the article for publication, acknowledges that the US Government retains a nonexclusive, paid-up, irrevocable, world-wide license to publish or reproduce the published form of this manuscript, or allow others to do so, for US Government purposes. This information was prepared as an account of work sponsored by an agency of the U.S. Government. Neither the U.S. Government nor any agency thereof, nor any of their employees, makes any warranty, express or implied, or assumes any legal liability or responsibility for the accuracy, completeness, or usefulness of any information, apparatus, product, or process disclosed, or represents that its use would not infringe privately owned rights. References herein to any specific commercial product, process, or service by trade name, trademark, manufacturer, or otherwise, does not necessarily constitute or imply its endorsement, recommendation, or favoring by the U.S. Government or any agency thereof. The views and opinions of authors expressed herein do not necessarily state or reflect those of the U.S. Government or any agency thereof.

\section{REFERENCES}

[1] J. L. Snelgrove, G. L. Hofman, M. K. Meyer, C. L. Trybus and T. C. Wienceck, "Development of Very-High-Density Low Enriched Uranium Fuels," J. Nucl. Eng. Des., no. 179, pp. 119-126, 1997.

[2] G. A. Moore, F. J. Rice, N. E. Woolstenhulme, J. Jue and B. H. Park, "Monolithic Fuel Fabrication Process Development at the Idaho National Laboratory," in RERTR 2009 Conference, Beijing, China, 2009.

[3] T. Totev, G. Hofman and M. Looby, "AA-Matpro - Handbook (Aluminum Materials Properties for Research Reactors)," Argonne National Laboratory, 2009.

[4] J. F. Jue, H. P. Blair, R. C. Curtis, A. M. Glenn and D. K. Dennis, "Fabrication of monolithic RERTR fuels by HIP," $J$. Nucl. Technol, vol. 172, no. 2, pp. 204-210, 2010.

[5] D. J. Alexander, K. D. Clarke, C. Liu, "Tensile Properties of 6061 Aluminum Alloy Materials, Los Alamos National Lab.

[6] K. Farrell and R. T. King, "Tensile Properties of NeutronIrradiated $6061 \mathrm{Al}$ Alloy in Annealed and Precipitation- hardened conditions," ORNL, Oak Ridge, Tennessee, 1979.

[7] D. M. Wachs, "Experiment Control Plan for the RERTR-12 Fuel Irradiation in te ATR," PLN-3248. Idaho National Laboratory Technical Report, 2012.

[8] G. A. Moore, "Fabrication Control Plan for the RERTR-12 Experiment," PLN-3254. INL Technical Report, 2010.

[9] G. A. Moore, "RERTR-12 As-Built Data Package," Idaho National Laboratory, 2010.

[10] H. Ozaltun and S. J. Miller, "Evaluation of Blister Behavior for U10Mo Mini fuel plates with cold rolled foils," in IMECE 2012, Houston, TX, 2012.

[11] M. K. Meyer, "Analysis of Low Blister Threshold Temperatures in the RERTR-12 and AFIP-4 Experiments," PLN-4155. INL Technical Report, 2012.

[12] D. M. Perez and M. A. Lillo, "INL/EXT-11-24282 - RERTR-6 Irradiation Summary Report," Idaho National Laboratory Technical Report, Idaho Falls, 2011.

[13] D. M. Perez and M. A. Lillo, " INL/EXT-11-24283 - RERTR7 Irradiation Summary Report," Idaho National Laboratory Technical Report, Idaho Falls, 2011.

[14] D. M. Perez and M. A. Lillo, "INL/EXT-10-18421 - RERTR-9 Irradiation Summary Report," Idaho National Laboratory Technical Report, Idaho Falls, 2011.

[15] D. M. Perez and M. A. Lillo, "INL/EXT-10-18456 - RERTR10 Irradiation Summary Report," INL, Idaho Falls, 2011.

[16] A. B. Robinson, "ECAR-689 - MCNP Calculated Gradients Across RERTR-9 Miniplates Irradiated in ATR," Idaho National Laboratory, Idaho Falls, 2011.

[17] D. L. Roswell, " ECAR-857 - MCNP-Calculated Gradients Across RERTR-10 Mini-plates Irradiated in ATR," Idaho National Laboratory, Idaho Falls, 2010.

[18] F. Rice, "Monolithic U-Mo Plate Blister Analysis," Idaho National Laboratory, 2011.

[19] R. W. Briggs, C. R. Clark and N. P. Hallinan, "RERTR-6 Fuel Plate Irradiation Experiments in the Adanced Test Reactor," Idaho Nation Laboratory, Idaho Falls, 2005.

[20] G. L. Hofman, Y. S. Kim and A. B. Robinson, "Fission Induced Swelling and Creep of Uranium Molybdenum Alloy Fuel," in RRFM 2009 Conference, Vienna, Austria, 2009.

[21] J. Rest and G. L. Hofman, "Experimental and Calculated Swelling Behavior of U-10 wt.\% Mo Under Low Irradiation Temperatures," in RERTR Meeting, 1998.

[22] K. H. Kim, J. M. Park, C. K. Kim, G. L. Hofman and M. K. Meyer, "Irradiation Behavior of atomized U-10wt\% Mo alloy aluminum matrix dispersion fuel meat at low temperature," $J$. Nucl. Eng. Des, vol. 211, pp. 229-235, 2002.

[23] E. F. Sturcken, "Irradiation Effects in Magnesium and Aluminum Alloys," J. Nucl. Mater., vol. 82, pp. 39-53, 1979.

[24] H. Ozaltun, H. Shen and P. Medvedev, "Numerical Simulation for Mechanical behavior of U10Mo monolithic miniplates," in IMECE2011, Denver, Colorado, 2011.

[25] H. Ozaltun, H. Shen and P. Medvedev, "Assessment of 
Residual Stresses on U10Mo alloy based Monolithic Miniplates during Hot Isostatic Pressing," J. Nucl. Mater., vol. 419, no. 1-3, pp. 76-84, 2011.

[26] H. Ozaltun, H. Shen and P. Medvedev, "Computational Evaluation for the Mechanical Behavior for U10Mo Fuel Miniplates subject to Thermal Cycling," submitted to J. Nucl. Eng. Des, 2012.

[27] M. D. Snyder and K. J. Bathe, "A solution procedure for thermo-elastic-plastic and creep problems," J. Nucl. Eng. Des., vol. 64, p. 49-80, 1981.

[28] A. A. Becker, T. H. Hyde and L. Xia, "Numerical analysis of creep on components," J. Strain Anal. Eng. Des., vol. 29, no. 3, p. 185-192, 1994.

[29] Abaqus Inc., "Rate-dependent plasticity: creep and swelling," in ABAQUS Theory Manual V6.10, Section 20.2.4., Providence/RI, Dassault Systemes Corp., 2010.

[30] Y. S. Kim and G. L. Hofman, "Fission product induced swelling of U-Mo alloy fuel,"J. Nucl. Mater, vol. 419, pp. 291-301, 2011.

[31] Y. S. Kim, G. L. Hofman, J. Rest and Y. S. Choo, "Analysis of Fission Gas Bubbles and Microstructures of Irradiated UMo Fuel," in RERTR 2009 Conference, Beijing, China, 2009.

[32] H. Ozaltun and S. J. Miller, "Finite Element Simulations of Monolithic Plates for the Conversion of High Performance Research Reactors: NBSR, MITR, MURR and AFIP," in IMECE2012, Houston, Texas, 2012.

[33] J. Rest, Y. S. Kim, G. L. Hofman, M. K. Meyer and S. L. Hayes, "U-Mo Fuels Handbook V.1.0," Argonne National Laboratory Internal Report, Idaho Falls / ID, 2006.

[34] D. E. Burkes, C. A. Papesch, A. P. Maddison, T. Hartmann and F. J. Rice, "Thermo-physical properties of DU-10 wt $\%$ Mo alloys," J. Nucl. Mater., vol. 403, pp. 160-166, 2010.

[35] D. E. Burkes, R. Prabhakaran, T. Hartmann and J. Jue, "Properties of DU-10 wt\% Mo alloys subjected to various post-rolling heat treatments," J. Nucl. Eng. Des, vol. 240, pp. 1332-1339, 2010.

[36] M. B. Waldron, R. C. Burnett and S. F. Pugh, "The Mechanical Properties of Uranium-Molybdenum Alloys," Atomic Energy Research Establishment, Harwell, Berkshire, UK, 1958.

[37] J. T. Mihalczo, "Reactivity Calibrations and Fission-Rate Distributions in an Unmoderated, Reflected UraniumMolybdenum Alloy Research Reactor," Oak Ridge National Laboratory, Oak Ridge, Tennessee, 1962.

[38] S. T. Polkinghorne and J. M. Lacy, "Thermophysical and Mechanical Properties of ATR Core Materials," Nuclear Reactor Research and Technology, 1991.

[39] Z. Zhang and H. W. Zhang, "Material behaviors and mechanical features in friction stir welding process," Int. J. Adv. Manuf. Technol., vol. 35, p. 86-100, 2007.

[40] S. F. Miller and A. J. Shih, "Thermo mechanical finite element modeling of the friction drilling process," J. Manuf. Sci. Eng., vol. 129, no. 3, pp. 531-539.
[41] Kaufman and J. Gilbert, "Properties of Alumiunum Alloys Fatigue Data and the Effects of Temperature, Product Form, and Processing," pp. 163-164, 2008.

[42] J. E. Gates, E. G. Bodine, J. C. Bell, A. A. Bauer and G. D. Calkins, "Stress-Strain Properties of Irradiated Uranium-10 w/o Molybdenum," Battelle Memorial Institute, Columbus, Ohio, 1958.

[43] J. M. Beeston, R. R. Hobbins, G. W. Gibson and W. C. Francis, "Development and irradiation performance of Uranium Aluminide fuels in test reactors," J. Nucl. Tech., vol. 49, pp. 136-149, 1980.

[44] D. R. Olander, "Fundamental Aspects of Nuclear Reactor Fuel Elements," Energy Research and Development Administration Technical Information Center, Oak Ridge/TN, 1976.

[45] A. T. Churchman, R. S. Barnes and A. H. Cottrell, "Effects of Heat and Pressure on the Swelling of Irradiated Uranium," $J$. Nucl. Eng., vol. 7, pp. 88-96, 1958.

[46] M. M. Hall and J. E. Flinn, "Stress State dependence of inreactor creep and swelling," J. Nucl. Mater., vol. 396, pp. 112129, 2010.

[47] A. Karahan, "Modeling of Thermo-Mechanical and Irradiation Behavior of Metallic and Oxide Fuels for Sodium Fast Reactors," Massachusetts Institute of Technology, 2009.

[48] T. Ogata and T. Yokoo, "Development and Validation of Alfus: An Irradiation Behavior Analysis Code for Metallic Fast Reactor Fuels," J. Nucl. Tech., vol. 128, pp. 113-123, 1999.

[49] J. R. Matthews and M. H. Wood, "A Simple Operational Gas Release and Swelling Model ii. Grain Boundary Gas," $J$. Nucl. Mater., vol. 91, pp. 241-256, 1980.

[50] F. Dherbey, F. Louchet, A. Mocellin and S. Leclercq, "Elevated Temperature Creep of polycrystalline uranium dioxide: from microscopic mechanisms to macroscopic behaviour," Acta Materialia, vol. 50, pp. 1495-1505, 2002.

[51] T. R. Kutty, C. B. Basak, A. Kumar and H. S. Kamat, "Creep Behaviour of d-phase of U-Zr system by impression creep technique," J. Nucl. Mater., vol. 408, pp. 90-95, 2011.

[52] M. S. Seltzer, A. H. Clauer and B. A. Wilcox, "The Stress dependence for high temperature creep of polycrystalline UO2," J. Nucl. Mater, vol. 34, pp. 351-353, 1970.

[53] M. S. Seltzer, A. H. Clauer and B. A. Wilcox, "The influence of stoichiometry on compression creep of polycrystalline UO2," J. Nucl. Mater., vol. 44, pp. 331-336, 1972.

[54] M. S. Seltzer, T. R. Wright and E. O. Speidel, "Creep Behavior of Low-Density Uranium Carbide-Base Alloys," $J$. Nucl. Mater., vol. 55, pp. 327-334, 1975.

[55] T. Kurasawa and T. Kikuchi, "Contribution of Uranium Diffusion on Creep Behavior of Uranium Dicarbide," J. Nucl. Mater., vol. 60, pp. 330-338, 1976.

[56] A. Karahan and M. S. Kazimi, "On the significance of modeling nuclear fuel with the right representation of physical phenomena," J. Nucl. Eng. Des, vol. 241, pp. 484-491, 2011. 